\title{
A FORMA DE FINANCIAMENTO DAS COMPANHIAS ABERTAS SOB OS PRESSUPOSTOS DA PECKING ORDER THEORY E TRADE OFF THEORY ${ }^{1}$
}

\section{THE FORM OF FINANCING OF LISTED COMPANIES UNDER THE AS- SUMPTIONS OF THE PECKING ORDER THEORY AND TRADE OFF THEORY \\ Tadeu Junior de Castro Gonçalves ${ }^{2}$ \\ Bacharelando em Ciências Contábeis pela Universidade Federal do Pará tadeu94junior@hotmail.com orcid.org/0000-0002-2888-1773}

\section{Anderson Roberto Pires e Silva}

Doutor em Ciências Contábeis pelo Programa Multiinstitucional UnB/UFPB/UFRN Professor da Universidade Federal do Pará andersonpires@hotmail.com orcid.org/0000-0002-1659-8153

\section{Pedro Borges Junior}

Mestre em Contabilidade e Finanças pela Universidade Federal do Espírito Santo Professor da Universidade Federal do Pará pedroborges@ufpa.br orcid.org/0000-0003-2281-1210

\section{RESUMO}

Objetivo: Investigar o perfil de financiamento das companhias de capital aberto no Brasil listadas na BM\&FBovespa, compreendendo o período de 2005 a 2015.

Fundamento: Teorias de finanças (Pecking Order Theory e Trade Off Theory) que explicam a política de financiamento adotada pelas companhias. As características institucionais: sistema legal, sistema financeiro e sistema contábil são fatores determinantes para se compreender a forma de financiamento das companhias de determinado país.

\footnotetext{
${ }_{1}$ Artigo recebido em: 19/05/2017. Revisado por pares em: 13/06/2017. Reformulado em: 24/08/2017. Recomendado para publicação em: 04/09/2017 por Adriana Fernandes de Vasconcelos (Editora Adjunta). Publicado em: 05/10/2017. Organização responsável pelo periódico: UFPB.

2 Endereço: Rua Augusto Corrêa, 1 - Guamá, Belém - PA, 66075-110

DOI: http://dx.doi.org/10.18405/recfin20180106

Os autores agradecem a todas as pessoas que contribuíram com o desenvolvimento deste trabalho. Agradecemos à nossa instituição de ensino, pesquisa e extensão, Universidade Federal do Pará, que, junto ao CNPQ nos apoiaram com o Programa de Apoio ao Doutor Pesquisador, fornecendo materiais e bolsa de iniciação científica.
} 
Método: Foi utilizada a metodologia proposta por Singh e Hamid (1992), que identifica como companhias financiam seus investimentos. Foram utilizados dados do ativo total, passivo total, dividendos pagos e lucro líquido.

Resultados: Em relação às fontes primárias de financiamento, os resultados indicaram o autofinanciamento como a principal fonte, sendo o endividamento a segunda opção, o que confirma a influência da Pecking Order Theory. Os resultados evidenciam que antes e depois da adoção do padrão contábil baseado em IFRS, a forma de financiamento das companhias da amostra não se alterou, assim, tais evidências permitem concluir que esse padrão contábil não é fator relevante para definir a forma como as companhias se financiam, mesmo sendo um padrão que incentive o financiamento pela emissão de ações.

Contribuições: Este estudo permite entender a influência das Pecking Order Theory e Trade Off Theory na forma como companhias abertas brasileiras se financiam. Contribui também para a reflexão sobre a fraca correlação existente entre formas de financiamentos e o padrão contábil adotado pelo país.

Palavras chave: Forma de financiamento. Pecking Order Theory. Trade Off Theory.

\section{ABSTRACT}

Objective: To investigate the financing profile of listed companies in Brazil listed on BM\&FBovespa, comprising the period from 2005 to 2015.

Background: Theories of finance (Pecking Order Theory and Trade Off Theory) that explain the financing policy adopted by the companies. The institutional characteristics: legal system, financial system and accounting system, are determining factors to understand the way of financing companies of a particular country.

Method: The methodology proposed by Singh and Hamid (1992) was used to identify how companies finance their investments. Total assets, total liabilities, dividends paid and net income were used.

Results: In relation to the primary sources of financing, the results indicated self-financing as the main source, with debt being the second option, which confirms the influence of the Pecking Order Theory. The results show that before and after the IFRS-based accounting standard were acquired, the form of financing of the sample companies did not change, thus, such evidence allows to conclude that this accounting standard is not a relevant factor to define the form that companies are financed, even though it is a pattern that encourages financing through the issuance of shares.

Contributions: This study allows us to understand the influence of the Pecking Order Theory and Trade Off Theory on the way Brazilian public companies finance themselves. It also contributes to reflection on the weak correlation between forms of financing and the accounting standard adopted by the country.

Keywords: Financing method. Pecking Order Theory. Trade Off Theory.

\section{INTRODUÇÃO}

Ao pensar sobre a forma de financiamento que as companhias utilizam para financiar seu crescimento e, consequentemente, sua estrutura de capital sob uma visão mais geral, observa-se uma questão ainda sem resposta e sujeita a uma série de hipóteses que poderão ser confirmadas ou não, dependendo de características e contextos específicos.

Esta situação pode ser entendida a partir das evidências de diversas pesquisas, como Modigliani e Miller (1958), Myers e Majluf (1984), Harris e Raviv (1991), Perobelli e Famá (2003), Procianoy e Schnorrenberger (2004), Albanez e Valle (2009), Bastos e Nakamura (2009), Padilha, Michels e Silva 
(2015) e Tani e Albanez (2016), que discutiram a estrutura de capital e/ou a forma de financiamento das companhias e, encontraram uma variedade de resultados, ora convergentes, ora divergentes, que são motivados por contextos, características institucionais, sistema legal, países e períodos diferentes.

Singh (1995) reforça essa ideia ao sinalizar diferenças na determinação da forma de financiamento das companhias, provocadas por fatores como a estrutura tributária, custo de transação e arranjos institucionais diferentes.

Quanto às características institucionais, Nobes (1998); K.T.R. Farias e Farias (2012) sustentam que em países de cultura tipo 1, com forte outsider equity e contabilidade classe A, as companhias possuem forte influência de recursos de investidores na composição de seu capital, enquanto que em países de cultura tipo 2 com fraco outsider equity e contabilidade classe B, as companhias possuem uma fraca presença de recursos de investidores na formação de seu capital, forçando a maioria destas a buscar recursos nos bancos.

Ball, Kothari e Robin (2000); Lopes e Walker (2008) defendem que o sistema legal que determinado país adota pode ajudar a entender a estrutura de capital ou a forma de financiamento que as companhias adotam. Segundo esses autores, países de características common law possuem tendências a terem em sua estrutura de capital uma maior frequência de recursos advindos do mercado de capitais, ou seja, de investidores, enquanto em países de características code law as companhias possuem tendências a possuírem em sua estrutura de capital uma maior frequência de recursos originários de bancos públicos e/ou privados.

O Brasil passa por um processo de transição, pois a partir da promulgação da Lei no 11.638 de dezembro de 2007 passou a adotar o padrão internacional de contabilidade, o qual possui característica common law, em tese, com uma maior participação de recursos de investidores na estrutura de capital das companhias (Ball, Kothari \& Robin, 2000) e consequentemente, sua contabilidade deveria migrar para classe A (cultura tipo 1) (Nobes, 1998). No entanto, Silva (2015) evidencia que mesmo o Brasil tendo adotado o padrão internacional de contabilidade baseado em IFRS, as companhias abertas brasileiras continuam financiadas por bancos públicos e/ou privados.

A partir deste contexto, e baseado nas Pecking Order Theory e na Trade Off Theory, tendo ainda como referência os estudos de Singh (1995), Zoneschain (1998) e Moreira e Puga (2001), no qual fizeram uso da metodologia proposta por Singh e Hamid (1992), questiona-se: qual a composição da estrutura de capital das companhias abertas brasileiras após a mudança da característica institucional do padrão contábil no Brasil? Assim, esta pesquisa tem por objetivo principal investigar o perfil de financiamento das companhias de capital aberto no Brasil listadas na Bolsa de Valores, Mercadorias e Futuros de São Paulo (BM\&FBovespa), compreendendo o período de 2005 a 2015.

Com a utilização de método similar de análise, porém em períodos distintos, com países e amostras diferentes, os estudos de Singh (1995); Zonenschain (1998); Moreira e Puga (2001) evidenciaram resultados que ora mostram-se convergentes e ora divergentes quanto à forma de financiamento das companhias e, consequentemente, sua estrutura de capital.

Singh (1995) e Moreira e Puga (2001), por exemplo, sugerem que as empresas brasileiras dependem fortemente da geração de recursos internos para financiar o seu crescimento, o que diverge do estudo de Zonenschain (1998), no período de longo prazo 1989/1996, no qual evidenciou que as empresas brasileiras possuem uma elevada participação de capital oriunda de emissões de ações.

Sendo assim, tais contradições deixam lacunas abertas para pensar na forma de financiamento das companhias, e ressalta a importância de realização de novos estudos. Neste caso, tomando como base a mudança de padrão contábil, que segundo Ball, Kothari e Robin (2000); Lopes e Walker (2008) influencia na forma como as companhias se financiam.

Estudos mais recentes como o de Procianoy e Schnorrenberger (2004); Bastos e Nakamura (2009); Correa, Basso e Nakamura (2013); Padilha, Michels e Silva (2015), entre outros, aventuraram- 
se na discussão relacionada a fatores e determinantes de estrutura de capital das companhias abertas. Neste raciocínio, Perobelli e Famá (2003) comentam sobre a importância dessa questão para a teoria de finanças, a qual levou ao desenvolvimento de várias proposições que buscavam estabelecer os possíveis fatores indutores da estrutura de capital das companhias.

De acordo com Albanez e Valle (2009) diversas teorias de finanças tentam explicar o que determina a política de financiamento adotada pelas companhias. Essas teorias sustentam a discussão referente à estrutura de capital e a forma de financiamento adotada pelas mesmas. Teorias que se iniciaram com o estudo de Modigliani e Miller (1958), passando por Jensen e Meckling (1976); Mayer (1984) e, Mayer e Majluf (1984). O presente estudo se sustentou nas teorias de Pecking Order, alimentada por uma hierarquia preferencial de fontes de financiamento e, Trade Off Theory, na qual se discute a existência de uma estrutura de capital ótima, ambas as teorias de Mayer (1984), e Mayer e Majluf (1984).

Assemelham-se, também, a esta pesquisa, o trabalho de Correa, Basso e Nakamura (2013), que buscou analisar o nível de endividamento das maiores empresas brasileiras à luz das teorias do Pecking Order e Trade Off. Outro estudo recente é o de Tani e Albanez (2016), o qual teve por objetivo verificar se a teoria do Pecking Order se aplica às decisões de financiamento de companhias abertas brasileiras que estão listadas em diferentes segmentos de governança corporativa da BM\&FBovespa, e outros (Medeiros \& Daher, 2005; Iquiapaza, Amaral \& Araújo, 2008), os quais relacionaram suas pesquisas às referidas teorias.

Além de dar continuidade às pesquisas referentes à estrutura de capital e à forma de financiamento, o presente estudo se diferencia dos anteriores nos seguintes aspectos: o período (2005 a 2015) em que a amostra é coletada, a análise trimestral dos dados e a abrangência dos setores (num total de 21) do mercado de capitais brasileiro.

Assim, espera-se contribuir com o mercado das companhias abertas brasileiras no sentido de evidenciar se as mesmas estão optando pelo autofinanciamento, por emissão de dívidas ou por emissões de ações para financiar seu crescimento. Este fato pode ser relevante para os investidores criarem um diagnóstico referente à preferência das companhias em captar recursos em que lhes proporcione suporte para tomada de decisões relacionadas à gestão dos novos e antigos investimentos.

Para a academia, a contribuição refere-se ao fato de poder relacionar e entender as teorias Pecking Order e Trade Off Theory no contexto das companhias brasileiras a partir da adoção do padrão internacional de contabilidade, e fazer com que se tenha uma visão crítica dos fatores que podem influenciar a preferência das companhias quanto à sua forma de financiamento, sustentada pelas teorias apontadas.

Este estudo também se justifica devido às divergências encontradas em estudos anteriores, constatando a necessidade de novas pesquisas envolvendo a temática abordada. Logo, torna-se relevante para contribuir com a área em questão.

O restante da pesquisa está estruturado da seguinte maneira. Na seção 2 são apresentadas revisões sobre temas que embasaram o estudo, como: características institucionais brasileiras, mercado de capitais e teorias de finanças. Na seção 3 é apresentada a definição da amostra e os procedimentos metodológicos utilizados, enquanto a seção 4 descreve os resultados obtidos. As seções 5 e 6 apresentam as conclusões e referências, respectivamente.

\section{REVISÃO DE LITERATURA}

Nesta seção são tratadas as características institucionais brasileiras, como sistema legal, sistema financeiro e contábil, e as teorias de finanças seminais, finalizando com a abordagem das teorias Pecking Order e Trade Off, propostas por Myers (1984) e Myers e Majluf (1984). 


\subsection{Características Institucionais Brasileiras}

As características institucionais como o sistema legal, sistema financeiro e sistema contábil são fatores determinantes para se compreender a estrutura de capital e a forma de financiamento das companhias de determinado país.

Silva (2015) discorre que, no caso específico do Brasil, o país sofre forte influência das características do mercado de crédito e de instituições financeiras, assim como das características do modelo legal Code law.

Partindo pela classificação do sistema legal, são identificados países com tradição do direito consuetudinário (common law) e países com tradição do direito romano (Code law). No sistema Common law as práticas contábeis são determinadas principalmente pelo setor privado (Ball, Kothari \& Robin, 2000). Dentre os países caracterizados por esse sistema, encontram-se: Austrália, Canadá, Reino Unido e Estados Unidos da América (EUA). De acordo com F.M. Costa, Lopes e Costa (2006), essa estrutura é menos regulamentada que as Code law e possui um mercado de capitais bem desenvolvido.

No sistema Code Law observa-se forte influência do governo na economia, a qual é norteada por um elevado grau de detalhamento de regras contábeis. Outras características comuns num contexto Code Law são: a concentração de poder na mão de poucos acionistas, a contabilidade se confunde com a área tributária, e existe uma menor demanda por informações públicas (F.M. Costa, Lopes \& A.C.O. Costa, 2006).

Nesse sistema, além do Brasil, encontram-se também países como Alemanha, França e Japão. Lopes e Walker (2008) comentam que o Brasil é um típico país em desenvolvimento, onde as demonstrações financeiras não estão preparadas para informar os investidores, mas para cumprir as exigências fiscais e outras exigências regulatórias.

Em relação ao sistema financeiro, Zysman (1983) identifica três tipos de sistemas. O primeiro se baseia em mercado de capitais, onde quem financia as companhias é o investidor por ações, este sistema é característico de países como EUA e Reino Unido. Albuquerque e Sicsú (2000) exemplificam que nesses países é privilegiado o canal do financiamento direto via emissão de papéis (ações, debêntures, etc.) pela investidora, que busca captar os recursos do público poupador.

O segundo sistema financeiro é administrado pelos governos sob a forma de crédito governamental. Entre os países com esta característica estão o Japão e França. Por fim, o terceiro sistema é baseado no crédito das instituições financeiras, dentre os países característicos estão a Alemanha e Brasil.

Neste contexto, Silva (2015) ressalta que no caso do Brasil, a criação de bancos como o Banco Nacional de Desenvolvimento (BNDES), Caixa Econômica Federal e Banco do Brasil, dentre outros, faz com que se pense que o país possui um sistema financeiro misto, baseado tanto no sistema financeiro das instituições, quanto no sistema governamental. Sendo assim, se observa certa dificuldade em enquadrar o Brasil exclusivamente em um dos sistemas financeiros indicados por Zysman (1983).

Albuquerque e Sicsú (2000) comentam que isso ocorre no Brasil porque o mercado de capitais e, especificamente o mercado de ações, é pouco desenvolvido, assim como não existe uma vocação do sistema financeiro brasileiro para se transformar em um sistema de crédito em qualquer das versões destacadas na classificação de Zysman (1983).

Na classificação do sistema contábil financeiro de um país foi desenvolvido por Nobes (1998) um modelo baseado ao nível de outsider equity. Conforme Silva (2015) outsider equity está relacionado com as características do sistema financeiro das companhias, as quais, segundo o autor, podem ter uma forte ou ampla participação de investidores no capital da empresa ou, ao contrário, uma fraca e restrita participação de investidores. 
No modelo desenvolvido por Nobes (1998) é realizado uma classificação de países embasados conforme as características das companhias.

Tabela 1: Modelo desenvolvido por Nobes (1998).

\begin{tabular}{lll}
\hline Países com cultura tipo1 & $\rightarrow$ Forte outsider equity & $\rightarrow$ Classe A - Contabilidade para investidores \\
Países com cultura tipo 2 & $\rightarrow$ Fraco outsider equity & $\rightarrow$ Classe B - Contabilidade para tributação e credores
\end{tabular}

Conforme a tabela 1, países com cultura tipo 1 apresentam uma ampla participação de investidores (Forte outsider equity); estes países possuem uma contabilidade caracterizada como Classe A, onde suas informações estão direcionadas aos investidores e potenciais investidores. Dentre os países que possuem forte outsider equity encontram-se os EUA, Austrália e Reino Unido. Já os países com cultura tipo 2 possuem fraca participação de investidores do mercado de capitais, ou seja, fraco outsider equity. Além disso, possuem uma contabilidade caracterizada como Classe B, a qual está voltada para tributação e credores, dentre os países que possuem fraco outsider equity, encontram-se França, Alemanha e Itália.

É verdade que o Brasil a partir da Lei 11.638/07, de modo geral, adotou um padrão contábil baseado nas normas internacionais de contabilidade (IFRS) que, em tese, é um padrão para países de cultura tipo 1 e, consequentemente, possuem uma forte participação de investidores financiando as empresas. Assim, passa-se a questionar se houveram alterações na hierarquia de financiamentos das companhias brasileiras a partir dessa mudança de procedimentos contábeis (Silva, 2015; K.T.R. Farias \& M.R.S. Farias, 2012).

\subsection{Teorias de finanças}

Diversos estudos referentes à determinantes de estrutura de capital têm despertado interesse tanto de pesquisas internacionais quanto nacionais (Myers \& Majluf, 1984; Myers, 1984; Perobelli \& Famá, 2003; Procianoy \& Schnorrenberger, 2004; Albanez \& Valle, 2009; Bastos \& Nakamura, 2009; Padilha, Michels \& Silva, 2015).

De acordo com Brito, Corrar e Batistella (2007) essa discussão deu origem a um grande esforço de pesquisa centrado na busca dos aspectos que explicam a forma como as companhias se financiam. Procianoy e Schnorrenberger (2004), Perobelli e Famá (2003) comentam que as teorias de finanças e as pesquisas internacionais indicam vários motivos para as decisões de políticas de financiamentos a serem adotadas.

Quanto aos precursores das teorias de finanças, Durand (1952) indicou a existência de uma estrutura ótima de financiamento; Modigliani e Miller (1958) defenderam, sob certas condições, a irrelevância da forma de financiamento das companhias. Tais afirmativas contraditórias fizeram com que estudos referentes à temática, como a forma de financiamento das companhias, se tornassem cada vez mais discutidos em finanças corporativas.

Tani e Albanez (2016) discorrem que Modigliani e Miller (1963) reconheceram que a presença de impostos e do benefício fiscal gerado pela dívida fazia com que a estrutura de capital da empresa fosse relevante para determinar o seu valor. Logo, a irrelevância da forma de financiamento das companhias foi reconsiderada pelos autores. Para Jensen e Meckling (1976) a estrutura ótima de capital é aquela que minimiza o custo da agência, assim, desenvolveram sua teoria sobre as implicações do relacionamento de agência entre executivos e os proprietários da firma.

Ao comentar a respeito das teorias (Pecking Order e Trade Off) de Myers e Majluf (1984) e Myers (1984), Silva (2015) discorre que estas se caracterizam como uma das principais fontes de pesquisa, na tentativa de se entender a forma como as companhias financiam seu crescimento. Seguindo esse raciocínio, o presente estudo sustenta-se nas teorias Pecking Order, alimentada por uma 
hierarquia preferencial de fontes de financiamento e pela teoria Trade Off, na qual se discute a existência de uma estrutura de capital ótima.

\subsubsection{Pecking Order Theory}

A teoria Pecking Order foi desenvolvida por Myers (1984) e Myers e Majluf (1984). Essa teoria é alimentada por uma hierarquia preferencial de fontes de financiamento, em decorrência da assimetria informacional, pois o plano de fundo para a existência dessa hierarquia é a assimetria de informações entre os gestores e os novos potenciais acionistas (Medeiros \& Daher, 2005).

Iquiapaza, Amaral e Araújo (2008) sinalizam que Myers e Majluf (1984) foram os pioneiros em relacionar a problemática da assimetria da informação à escolha da fonte de financiamento, assinalando que esta pode influenciar na imagem e no valor da empresa.

O termo "Assimetria de informação" refere-se, em uma dada transação, às informações privilegiadas que somente um dos agentes atuantes possui (Iquiapaza, Amaral \& Araújo, 2008). Neste contexto, Fonseca, Silveira e Hiratuka (2016) afirmam que o problema da informação assimétrica seria proveniente do fato dos gestores terem acesso a informações referentes aos resultados operacionais e às oportunidades de investimento da empresa não disponíveis no mercado.

Compreendendo o período de 1997 a 2007, Albanez e Valle (2009) se propuseram a analisar o pressuposto central da Pecking Order Theory e verificar se a assimetria da informação influencia nas decisões de financiamento das companhias abertas brasileiras. O principal resultado do estudo mostrou que as empresas consideradas com menor grau de assimetria informacional são mais endividadas que as demais na análise do nível de endividamento total, resultado contrário à teoria do Pecking Order.

A hierarquia de fontes de financiamentos que se baseia o modelo proposto por Myers e Majluf (1984) e Myers (1984) inicia-se na utilização de capital próprio, seguido de financiamentos externos por meio de emissão de dívidas, e, por último, a emissão de ações. Esta hierarquia se justifica pelo fato dos recursos gerados internamente (lucros retidos, por exemplo) não terem custos de transação para a empresa se autofinanciar.

Em seguida, tem-se a emissão de dívidas, a qual, num contexto de mercado, pode sinalizar um panorama positivo sobre a empresa, demonstrando otimismo em relação ao seu futuro. Por fim, tem-se a captação de recursos de terceiros via emissão de ações, a qual pode sinalizar, em certo contexto de mercado, um pessimismo com relação a seus investimentos futuros, pois pode representar a divisão de perdas com os novos acionistas (Brealey, Myers \& Allen, 2006).

Estudos foram desenvolvidos (França, S.I.F. Santos, Sandoval \& A.P. Santos, 2016; Kaveski, Hall, Degenhart, Vogt \& Hein, 2015; Correa, Basso \& Nakamura, 2013; Bastos \& Nakamura, 2009; Iquiapaza, Amaral \& Araujo, 2008) no sentido de investigar a realidade das empresas brasileiras com relação à aplicação das ideias centrais da Pecking Order Theory, ou seja, se o autofinanciamento é a fonte de recursos preferida pelas companhias, e se a emissão de dívidas é preferível às emissões de ações quanto à preferência pelo financiamento externo.

Assim, Bastos e Nakamura (2009), ao investigarem dados de 297 companhias de diversos setores da economia pertencentes ao Brasil, México e Chile, sob a perspectiva das Trade Off Theory, Pecking Order Theory, Teoria da Assimetria da informação e Teoria da Agência, concluíram que a Pecking Order Theory é a que melhor explica os resultados para o Brasil e México, enquanto para as companhias Chilenas, além da Pecking Order Theory, a Trade Off Theory exerce forte influência sobre a estrutura de capital das companhias. Em outro estudo, Correa, Basso e Nakamura (2013) sugerem que a teoria do Pecking Order é mais consistente do que a teoria do Trade Off para explicar a forma de financiamento adotada pelas companhias abertas brasileiras. 
França et al. (2016), ao discutirem resultados de pesquisa sobre formas de financiamento do setor de energia elétrica no Brasil, evidenciaram que tais empresas são preponderantemente financiadas por capital próprio, seguindo as ideias da Pecking Order Theory.

A pesquisa de Kaveski et al (2015) mostrou que mais de uma teoria pode apoiar o entendimento da forma de financiamento adotada pelas companhias. Nesse sentido, ao analisarem determinantes de estrutura de capital das empresas brasileiras de capital aberto de um único setor financeiro, à luz das teorias Trade off e Pecking Order, os autores concluíram que as empresas brasileiras do agronegócio estão apoiadas tanto na teoria do Trade Off quanto na Pecking Order.

No entanto, Iquiapaza, Amaral e Araújo (2008) encontraram resultados diferentes dos estudos já mencionados, pois ao investigarem dados de 313 empresas listadas na BM\&FBovespa, indicaram que unicamente as empresas de menor tamanho da amostra, as de menor lucratividade e as de baixo crescimento, apresentam aderência considerada "fraca" às previsões da Pecking Order Theory; logo a teoria não pode ser considerada uma teoria geral para explicar a estrutura de capital das empresas.

\subsubsection{Trade Off Theory}

Ao contrário da Pecking Order Theory, a teoria Trade Off discute a existência de uma estrutura de capital ótima. De acordo com Silva, Gonçalves e Leite (2016), esta corrente teórica preconiza que as organizações devem buscar uma estrutura de capital que maximize os benefícios e minimize os custos de endividamento. Conforme Medeiros e Daher (2005) se supõe que a empresa estabelece uma meta de endividamento e procura alcança-la ao longo do tempo.

Para Myers (1984), a estrutura de capital ótima é atingida quando o equilíbrio dos efeitos que os impostos auferem sobre dívidas e custos de falência ocorrem em relação à alavancagem. Neste contexto, Kaveski et al. (2015) discorrem que a empresa aumenta o endividamento até o momento em que o benefício fiscal relacionado às dívidas for compensado por meio da elevação do valor presente do custo das dificuldades financeiras encontradas.

Brito e Lima (2005) discorrem que como as firmas efetivamente combinam dívida e recursos próprios em sua estrutura de capital, se desenvolveu a teoria de Trade Off do endividamento, onde a alavancagem ótima é o resultado da ponderação entre seus custos e benefícios.

Myers (1984) discorre que as empresas que elevarem seu endividamento também elevam o seu valor, entretanto, ao se elevar o endividamento, os custos de dificuldades financeiras também aumentam.

No Brasil, a ênfase dos estudos está relacionada mais à Pecking Order Theory do que a Trade Off Theory, pois alguns resultados (Bastos \& Nakamura, 2009; Correa, Basso \& Nakamura, 2013), apontam maior consistência da referida teoria do que a Trade off para explicar as formas que as companhias brasileiras buscam para financiar seu crescimento.

Entretanto, outros estudos (Nascimento,2012; Padinha, Michels \& Silva, 2015) apresentaram resultados que se apoiam na referida teoria.

Padilha, Michels e Silva (2015), por exemplo, verificaram as determinantes de estrutura de capital das empresas de alta tecnologia dos países do G-20, compreendendo o período de 2010 a 2013, os resultados mostraram que as determinantes de estrutura de capital das empresas estudadas são: rentabilidade, tangibilidade e crescimento, e o estudo reitera que as empresas analisadas do setor de alta tecnologia estão apoiadas na teoria do Trade off em função de sua estrutura de capital.

Em síntese, observa-se a importância das características institucionais para o entendimento da forma de como as companhias abertas de determinado país se financiam, ou seja, pelo autofinanciamento, pela emissão de dívidas ou pela emissão de ações. Nesse sentido, a Pecking Order Theory e 
Trade off Theory expostas neste estudo passam a ser fundamentais para o entendimento e/ou interpretação da forma de financiamento, e consequente estrutura de capital das companhias pesquisadas.

\section{PROCEDIMENTOS METODOLÓGICOS}

Este estudo teve por objetivo principal investigar a forma de financiamento das companhias brasileiras de capital aberto listadas na BM\&FBovespa, compreendendo os anos de 2005 a 2015. Para o alcance deste objetivo foi utilizada a metodologia proposta por Singh e Hamid (1992). A escolha deste procedimento metodológico justifica-se pelo fato de conseguir analisar, por meio de dados como ativo total, passivo total, dividendos pagos e lucro líquido, a forma como as companhias financiam seus investimentos. Por este modelo, o crescimento da firma é medido pela variação do capital de longo prazo, obtido através da diferença entre o total do ativo e o passivo de curto prazo (Moreira \& Puga, 2001).

Este crescimento é decomposto em três partes (autofinanciamento, financiamento externo por endividamento e financiamento externo por emissão de ações), sempre trabalhando com médias para os conjuntos de companhias analisadas. Estudos anteriores, como os realizados por Zoneschain (1998) e Moreira e Puga (2001), testaram este grupo de variáveis da metodologia proposta por Singh e Hamid (1992) para analisar as formas de financiamentos adotadas pelas companhias pesquisadas.

Ressalta-se que a metodologia proposta por Singh e Hamid (1992), além do grupo que analisa a forma de financiamento, também possui outros grupos de análise, como tamanho da firma e medida de performance; estrutura de capital e comportamento dos preços no mercado acionário e do retorno de dividendos.

No entanto, assim como em Zoneschain (1998) e Moreira e Puga (2001), foi adotado nesta pesquisa apenas o grupo de variáveis que analisa a forma de financiamento das companhias. Essa adoção justifica-se em virtude da abrangência da amostra, a qual se limita a uma quantidade inferior, em virtude da ausência de alguns dados das companhias (painel desbalanceado).

A seguir, destacam-se as fórmulas desenvolvidas por Singh e Hamid (1992) para o cálculo dos três indicadores da forma de financiamento das companhias. Ressalta-se que para o tratamento dos dados usou-se o software Microsoft EXCEL.

- Financiamento Interno: representa a parcela que é financiada com recursos internos, através de lucros retidos. Calculado pelo somatório da diferença entre lucros líquidos e dividendos pagos, dividido pelo somatório da variação das diferenças entre ativo total e o passivo circulante.

$$
\frac{\sum_{\mathrm{p}+1}^{\mathrm{m}}(\text { Lucro líquido-Dividendos pagos })}{\left.\sum_{\mathrm{p}+1}^{\mathrm{m}} \Delta \text { (Ativo total-Passivo Circulante }\right)}
$$

Onde: $\mathrm{m}=$ último mês de trimestre; $\mathrm{p}=$ primeiro mês de trimestre.

- Financiamento Externo através de Emissão de Dívida: $O$ endividamento foi calculado pelo somatório das variações do exigível de longo prazo, dividido pela somatório das variações das diferenças entre ativo total e o passivo circulante.

$$
\frac{\sum_{\mathrm{p}+1}^{\mathrm{m}} \Delta(\text { Exigível a longo prazo })}{\sum_{\mathrm{p}+1}^{\mathrm{m}} \Delta(\text { Ativo total-Passivo Circulante })}
$$

Onde: $\mathrm{m}=$ último mês de trimestre; $\mathrm{p}=$ primeiro mês de trimestre. 
- Financiamento Externo através de Emissão de Ações: calculado por resíduo de financiamento interno deduzido do endividamento.

$$
1 \text { - (Financiamento interno) - (Endividamento) }
$$

Como quesito do modelo, foi calculada a média trimestral dos anos pesquisados, e a média do período analisado (2005/2015). A amostra inicial constituiu-se de 374 companhias de capital aberto, da classe ON (Ações Ordinárias), de diversos setores negociadas na BM\&Fbovespa. Os dados trimestrais do ativo total, passivo total, dividendos pagos e lucro líquido foram retirados do banco de dados da Economatica ${ }^{\circledR}$, compreendendo o período de 2005 a 2015.

A distribuição setorial das empresas deu-se da seguinte forma: Agro e pesca (5), alimentos e bebidas (14), comércio (19), construção (22), eletrônicos (6), energia elétrica (44), finanças e seguros (31), fundos (1), maquinas industriais (5), mineração (5), minerais não metais (4), papel e celulose (4), petróleo e gás (8), química (10), siderurgia e metal (21), software e dados (6), telecomunicações (12), têxtil (24), transporte e serviços (20), veículos e peças (16) e outros (97), totalizando 21 setores de mercado.

Além de serem eliminadas as companhias em que não havia dados no painel, saldos nulos foram convertidos em vazios, foram utilizados dados referentes da classe ON (ações ordinárias) em função das demais classes apresentarem dados idênticos.

Para garantir consistência dos resultados, foram realizados ajustes nos dados, e estes ajustes de consistência foram realizados em pesquisas anteriores (Singh \& Hamid, 1992; Singh, 1995; Zonenschain, 1998; Moreira \& Puga, 2001), onde utilizaram a mesma metodologia de mapeamento da forma de financiamento das companhias. Estes ajustes fizeram com que somente companhias que apresentassem dados em todos os períodos trimestrais da amostra (2005 a 2015) fossem estudadas.

Ainda em relação aos ajustes dos dados, assim como Zonenschain (1998) e Moreira e Puga (2001), e com o objetivo de eliminar possíveis outliers, foram propostos os seguintes critérios para eliminação de dados: Para o autofinanciamento e endividamento foram excluídas companhias que não apresentaram percentual de financiamento situado entre $-100 \%$ e superior a $+200 \%$. Para a emissão de dívidas foram excluídos os indicadores do financiamento inferiores a $-100 \%$ e superiores a $+100 \%$.

Justifica-se que estes critérios tiveram por objetivo evitar índices que tendem ao infinito, em virtude de um denominador próximo de zero. Com base nesses critérios, o número de companhias com dados necessários para o propósito do estudo ficou inferior à amostra inicial.

Ressalta-se que o tamanho da amostra foi diminuindo à medida que foram sendo realizados os critérios de consistência apresentados pela metodologia. Devido aos dados desbalanceados, a amostra final correspondeu a 12,03\% da amostra inicial, ou seja, 45 companhias.

Após a aplicação dos critérios de consistência dos resultados, a quantidade de setores do mercado que consistia de 21 na amostra inicial passou para 15 setores na amostra final. Logo, os segmentos que restaram foram: alimentos e bebidas, construção, eletroeletrônicos, energia elétrica, finanças e seguros, mineração, minerais não metais, papel e celulose, petróleo e gás, química, telecomunicações, têxtil, transporte e serviços, veículos e peças e outros.

\section{RESULTADOS E DISCUSSÕES}

Na primeira etapa será apresentada a estatística descritiva com foco na média, desvio padrão, máximo e mínimo dos índices de autofinanciamento, endividamento e emissão de ações. Posteriormente, será evidenciada a principal fonte de financiamento da amostra, seguido pela 
fonte secundária de financiamento das companhias. Concomitantes, serão feitas referências às teorias abordadas, trazendo evidências daquela que melhor explica o comportamento do resultado obtido. Por fim, é apresentada uma comparação com estudos anteriores que utilizaram a metodologia de Singh e Hamid (1992).

\subsection{Estatísticas descritivas}

Tabela 2: Estatística Descritiva (Em \%)

\begin{tabular}{c|l|l|l}
\hline & Autofinanciamento & Endividamento & Emissão de Ações \\
\hline Média & 1.39 & 1.37 & 0.98 \\
\hline Desvio-Padrão & 0.28 & 0.27 & 0.39 \\
\hline Máximo & 1.93 & 1.98 & 1.71 \\
\hline Mínimo & 1.00 & 1.00 & 0.19 \\
\hline
\end{tabular}

Fonte: Dados da pesquisa.

A média de autofinanciamento foi de $1.39 \%$, ao passo que a média de endividamento foi de $1.37 \%$. Após aplicação de um teste t de student para diferença de médias, ficou evidente que não há diferença estatística significativa entre os dois procedimentos de financiamento (conforme tabela 3 - Teste de diferença de média). Ou seja, entre esses dois não há preferência de fonte de financiamento. Entretanto, ambos são preferíveis em relação ao financiamento externo, que apresentou média igual a $0,98 \%$.

Tabela 3: Teste de diferença de média

\begin{tabular}{|c|c|c|c|c|c|c|}
\hline Variable & Obs & Mean & Std. Err. & Std. Dev. & $95 \%$ Conf. & Intervalo \\
\hline var1 & 22 & 1.548709 & .0541375 & .2539272 & 1.436124 & 1.661294 \\
\hline var2 & 22 & 1.547571 & .0531232 & .2491699 & 1.437095 & 1.658047 \\
\hline diff & 22 & .0011381 & .0737911 & .346111 & -.152319 & .1545951 \\
\hline \multicolumn{5}{|c|}{ mean $($ diff $)=$ mean $($ var1 - var2) } & \multicolumn{2}{|c|}{$t=0.0154$} \\
\hline \multicolumn{5}{|c|}{ Ho: mean $($ diff $)=0$} & \multicolumn{2}{|c|}{ degrees of freedom $=21$} \\
\hline \multicolumn{3}{|c|}{ Ha: mean (diff $)<0$} & \multicolumn{2}{|c|}{ Ha: mean(diff) $!=0$} & \multicolumn{2}{|c|}{ Ha: mean $($ diff $)>0$} \\
\hline \multicolumn{3}{|c|}{$\operatorname{Pr}(\mathrm{T}<\mathrm{t})=0.5061$} & \multicolumn{2}{|c|}{$\operatorname{Pr}(|\mathrm{T}|>|\mathrm{t}|)=0.9878$} & $>t)=0.4939$ & \\
\hline
\end{tabular}

Fonte: Elaborado pelos autores.

Ha: mean(diff) $<0$ testa se a diferença é menor do que zero.

Ha: mean(diff) != 0 testa se existe diferença entre as médias.

Ha: mean(diff) $>0$ testa se a diferença é maior do que zero.

Os testes mostram que não há diferença significativa entre as formas de financiamentos estudadas (p-valor para existência de diferença de média igual a 0,9878). Logo, 51\% não diverge de $49 \%$, sendo as duas formas de financiamentos (autofinanciamento e endividamento) igualmente válidas.

Conforme explicado nas fórmulas, os índices representam o nível de comprometimento dos recursos das empresas, sendo que para cada fórmula o índice demonstra se a companhia utiliza mais o autofinanciamento, o endividamento ou o financiamento externo. $\mathrm{O}$ maior dos três é que define a preferência da companhia.

Neste sentido, se observa a preferência das empresas pelo autofinanciamento ou endividamento, em detrimento ao financiamento externo por meio de abertura de capital. Isso está de acordo com a Pecking Order Theory, com sua hierarquização de fontes de financiamento, sendo o autofinanciamento $(51 \%)$ a principal opção de capitação de recursos, conforme previram Myers e Majluf (1984). 


\subsection{Fonte primária de financiamento das companhias.}

Figura 1: Principal fonte de financiamento das companhias abertas no Brasil 2005 - 2015. (Em \%).

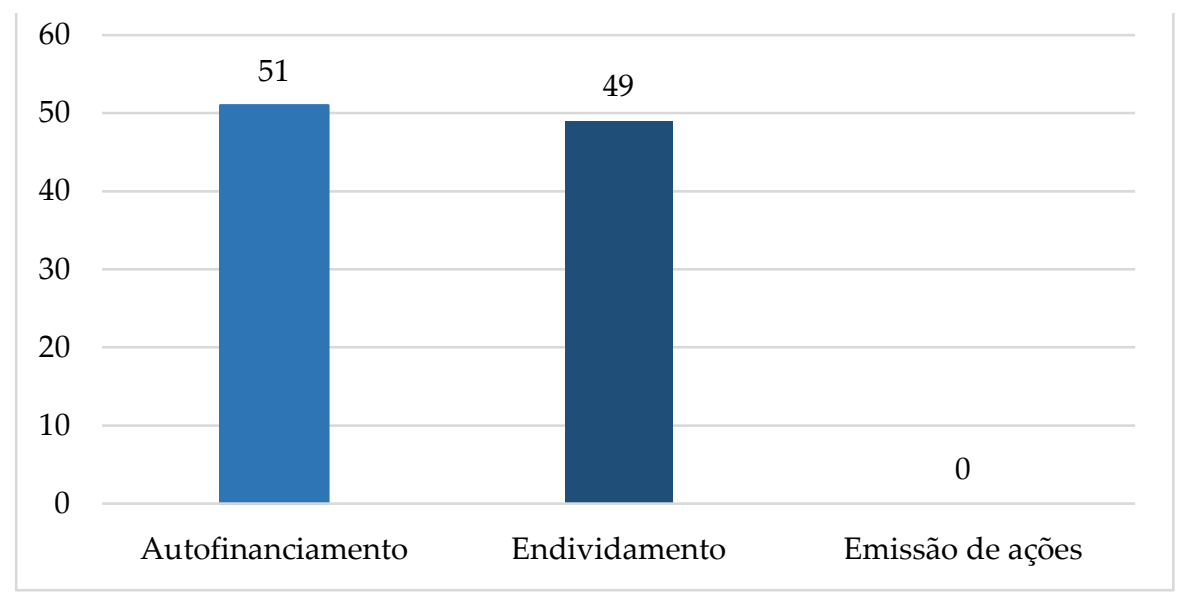

Fonte: Dados da pesquisa.

Os resultados apresentados na figura 1 demonstram que as companhias da amostra preferem como fonte primária de financiamento de seu crescimento o autofinanciamento, que correspondeu a 51\% da amostra. Como fonte secundária de financiamento está a emissão de dívidas, correspondendo a $49 \%$. Ressalta-se que ao investigar as fontes primarias de recursos, o financiamento externo via emissão de ações não apresentou evidências de utilização por parte das empresas.

A ausência de financiamento através da emissão de ações como fonte primária de investimento pode ser justificada pelos métodos de consistência dos resultados utilizados nos dados em painel, que reduziu a amostra a $12,03 \%$ da amostra inicial, isto é, a 45 companhias.

Ressalta-se que outras pesquisas que utilizaram a mesma metodologia tiveram suas amostras reduzidas. Por exemplo, Zonenschain (1998) se propôs a estudar 216 empresas industriais de capital aberto nos anos de 1989 a 1996, entretanto, só foi possível analisar 97 empresas. Nesta pesquisa, ocorreu uma redução de companhias bem maior devido ao período de análise e aos diversos setores de companhias negociadas na BM\&FBovespa.

No entanto, neste primeiro momento de análise, já se torna possível observar a influência da Pecking Order Theory com sua hierarquização de fontes de financiamento (Myers \& Majluf, 1984), sendo o autofinanciamento a principal opção de captação de recursos, posteriormente está o endividamento.

\subsection{Fonte secundária de financiamento das companhias.}

Figura 2: Fonte secundária de financiamento das companhias abertas no Brasil 2005 - 2015 (Em \%).

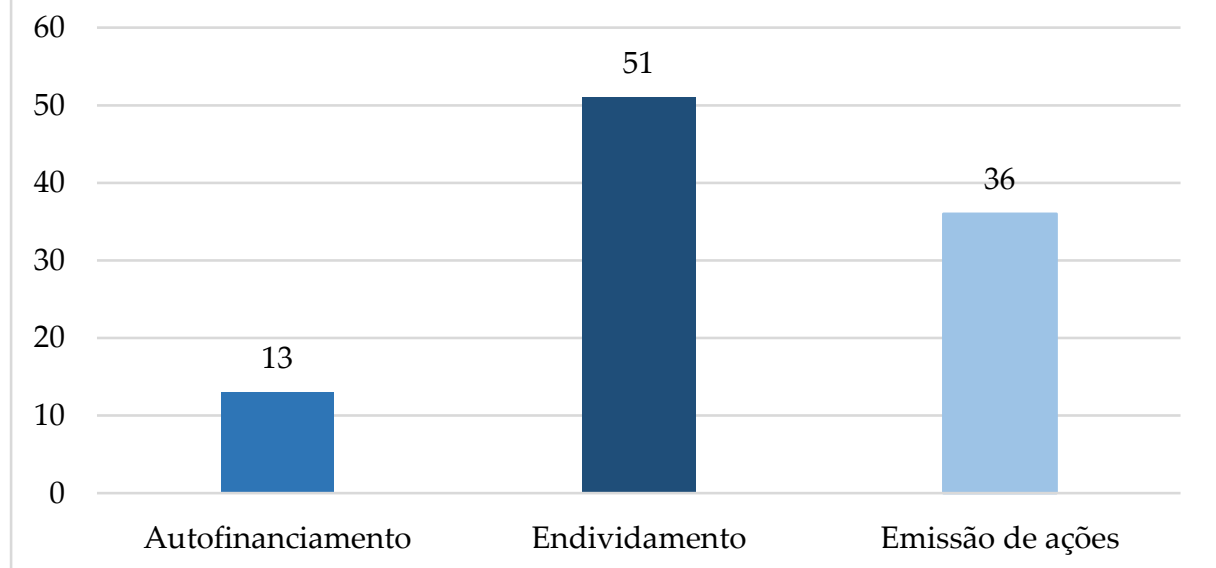

Fonte: Dados da pesquisa. 
A figura 2 demonstra que ao investigar as companhias que optam pela fonte de financiamento por meio da emissão de dívidas, que correspondeu a 51\%, é preferível para estas companhias como segunda opção de financiamento dos investimentos, o financiamento externo via emissão de ações, que correspondeu a 36\%.

Com porcentagem menor, se encontra o autofinanciamento, com 13\% da amostra. Ou seja, daqueles $49 \%$ que adotaram como forma de financiamento a emissão de dívidas, ao se optar por outras formas de financiamentos, se têm como preferência a emissão de ações (36\%) e posteriormente o autofinanciamento (13\%). Logo, este resultado pode ser interpretado pela Trade Off Theory, que busca uma melhor relação custo-benefício para as companhias no que diz respeito ao capital próprio e o capital de terceiros (Bastos \& Nakamura, 2009; Myers \& Majluf, 1984).

Esta preferência por emissão de dívidas pode ser entendida por meio da classificação proposta por Zysman (1983) em relação aos sistemas financeiros, que podem se encontrar baseados tanto no mercado de capitais, quanto no mercado de crédito de instituições financeiras, e/ou no mercado baseado em créditos governamentais. Este resultado reforça as afirmações de Silva (2015), quando discorre que, no caso do Brasil, o sistema financeiro é considerado misto, devido à criação pelo governo de bancos, como o Banco Nacional de Desenvolvimento Econômico e Social (BNDES). Dessa forma, o sistema financeiro nacional pode ser baseado tanto no crédito governamental quanto no crédito bancário.

Outra justificativa para estes resultados em relação às fontes secundárias, seriam as características institucionais do Brasil, com um perfil de um modelo code law (Ball, Kothari e Robin, 2000) e um fraco outsider equity, isto é, pouco capital de investidores compondo a estrutura de capital das companhias (Nobes, 1998).

A considerável presença de financiamento adotada pelas companhias de capital aberto através da emissão de dívidas, geralmente advindas de transações com instituições financeiras, pode ser reflexo da característica institucional forma de financiamento, pois no caso do Brasil ainda é forte a participação dos bancos como agente financiador das companhias, mesmo sendo aquelas de capital aberto (Silva, 2015; Lopes \& Walker, 2008).

O aparecimento da fonte de financiamento via emissão de ações (36\%) também pode ser explicado pelo sistema legal adotado no Brasil, pois apesar de possuir características code law, adotou nos últimos anos um modelo contábil baseado em características common law, motivado pelo aumento de investidores no mercado de capitais brasileiro, o que pode indicar uma mudança de contabilidade, ou seja, a mudança de uma contabilidade focada na tributação e informações voltadas aos credores, para uma contabilidade mais direcionada aos investidores (Silva, 2015; Farais \& Farias, 2012; Lopes \& Walker, 2008).

Diante das transformações ocorridas no Brasil, ocasionadas por um ambiente macroeconômico desde o início da década de 90, transformações que envolveram, por exemplo, a abertura comercial, a liberação cambial, taxa de juros, crise das instituições de crédito e a instabilidade gerada pela inflação de 1994, fez com que Zonenschain (1998) analisasse dois períodos, o primeiro (curto prazo) abrangeu os anos de 1995 a 1996, enquanto o segundo (longo prazo) abrangeu os anos de 1989 a 1996. Logo, para o estudo de Zonenschain (1998), têm-se duas análises. 
Figura 3: Comparação da fonte de financiamento das companhias abertas no Brasil (Em \%).

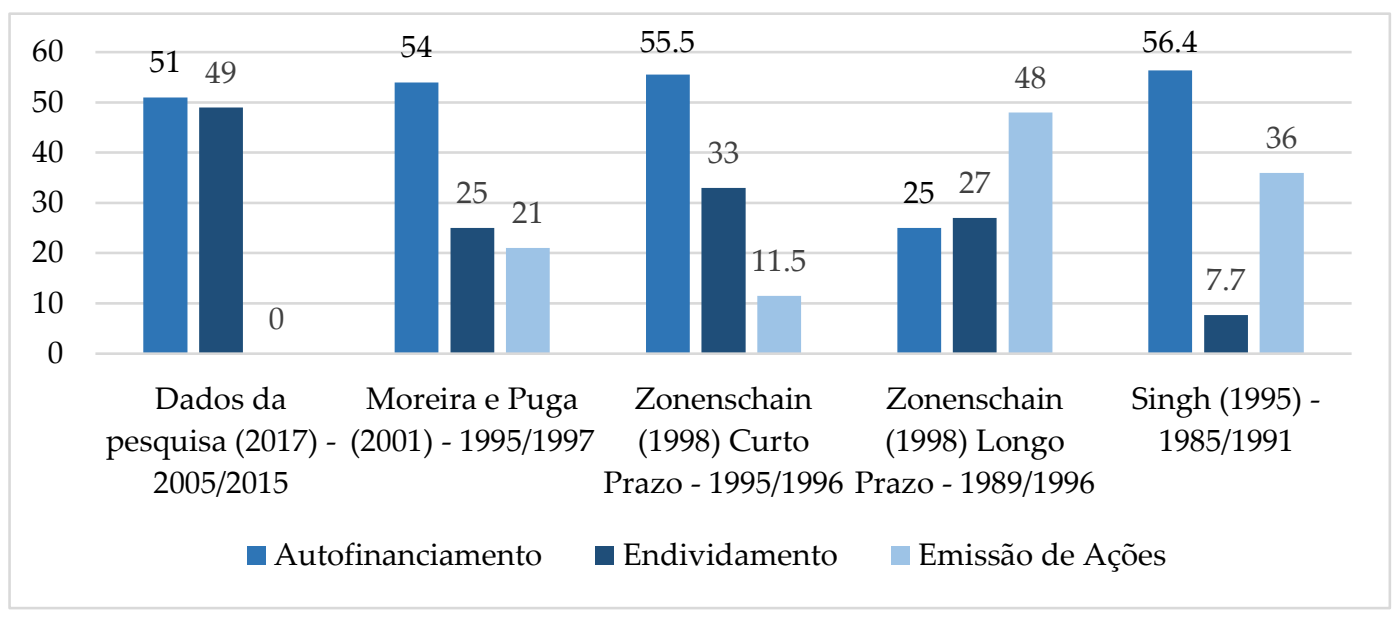

Fonte: Adaptado de Moreira e Puga (2001).

Apesar da amostra da presente pesquisa analisar diferentes segmentos, ao contrário dos estudos anteriores realizados por Moreira e Puga (2001), Zonenschain (1998) e Singh (1995), nos quais estudaram companhias industriais, os resultados deste estudo corroboraram com os resultados dos estudos anteriores, no que diz respeito ao autofinanciamento como principal fonte de financiamento das companhias abertas no Brasil.

Observa-se que no presente estudo foi possível evidenciar que 51\% das companhias da amostra optam pelo autofinanciamento. Moreira e Puga (2001), por sua vez, evidenciaram 54\%. Zonenschain (1998), no período de curto prazo (dos anos 1995 a 1996) obtiveram 55,5\% e Singh (1995) obteve o maior percentual referente ao autofinanciamento, representando $56,4 \%$.

Logo, observa-se mais uma vez a confirmação da Pecking Order Theory com sua hierarquização de fontes de financiamento (Myers \& Majluf, 1984), para explicar as formas de financiamento das companhias, nos estudos considerados naanálise comparativa.

No entendimento de Singh (1995), a percentagem de 56,4\% de autofinanciamento se expressou por motivos como: baixo desenvolvimento de fontes externas de financiamento, e por taxas elevadas de juros praticadas por financiadores. Estes resultados também podem estar vinculados às características institucionais do país, como o sistema legal Code law e o sistema financeiro das empresas dos países com cultura tipo 2 (fraco outsider equity).

Quanto às divergências encontradas, têm-se os resultados em longo prazo de Zonenschain (1998), que correspondeu aos anos de 1989 a 1996, em que a emissão de ações correspondeu a 48\%, seguido de endividamento (27\%) e finalizando pelo autofinanciamento, representado por $25 \%$ das companhias estudadas. Tais resultados divergem dos pressupostos da Pecking Order Theory, no entanto, podem ser interpretados pela Trade Off Theory, que vai em busca de uma melhor relação do custo-benefício entre o capital auferido e seu respectivo custo.

Outro resultado divergente refere-se aos achados de Singh (1995), no qual o autofinanciamento representou $56,4 \%$, no entanto, a segunda opção foi a forma de financiamento via emissão de ações, representando $36 \%$ da amostra, já o endividamento correspondeu a terceira opção, indicando a porcentagem de 7,7\%. Estes resultados também divergem da Pecking Order Theory, entretanto, podem ser explicados pela Trade Off Theory. Singh (1995) aponta como justificativa para tais resultados, a instabilidade macroeconômica e a crise das instituições de crédito do Estado naquela época.

Observa-se, pelos diversos estudos, que tanto a Pecking Order theory quanto a Trade Off Theory podem ser utilizadas para entender as formas de financiamentos escolhidas pelas companhias, o que reforça os dizeres de Kaveski et al (2015) que mostraram a possibilidade de mais de uma teoria poder apoiar o entendimento da forma de financiamento adotada pelas companhias. 
Neste sentido, os resultados da pesquisa, obtidos através da metodologia proposta por Singh e Hamid (1992), indicaram que o perfil de financiamento das companhias abertas brasileiras durante o período de 2005 a 2015, teve como fonte principal o autofinanciamento, seguida pela emissão de dívidas, e por fim, a emissão de ações. Esta ordem condiz com a hierarquia na forma de financiamento que sustenta a teoria do Pecking Order. Porém, ao se analisar a fonte secundária de financiamento, observa-se que a Trade Off Theory se adequaria melhor para explicar o contexto das companhias brasileiras durante o período de investigação.

\section{CONSIDERAÇÕES FINAIS}

Partindo do pressuposto de que a estrutura de financiamento das companhias pode ser influenciada por características institucionais como o sistema legal e o modelo contábil adotado pelo país e, considerando que o Brasil passou a adotar o padrão internacional de contabilidade baseado em IFRS, que tem como uma de suas características a maior participação de recursos de investidores na estrutura de capital das companhias, evidências apontam que as companhias abertas brasileiras continuam a serem financiadas por bancos públicos e/ou privados (Silva, 2015).

Assim, a presente pesquisa objetivou investigar o perfil de financiamento das companhias de capital aberto no Brasil listadas na BM\&FBovespa, compreendendo o período de 2005 a 2015. Para tanto, utilizou-se o modelo proposto por Singh e Hamid (1992), o qual decompõe a forma de financiamento das companhias em autofinanciamento, emissão de dívidas (endividamento) e emissão de ações. Dentre as diversas teorias de finanças propostas para entender a forma de financiamento das companhias, optou-se nesta pesquisa pela Pecking Order Theory e pela Trade Off Theory.

Os resultados indicaram que o autofinanciamento é a principal fonte de financiamento das companhias, representando $51 \%$ da amostra, enquanto o financiamento externo, através do endividamento, representou $49 \%$ da amostra. Logo, com esse resultado para financiamento primário das companhias, foi possível observar a influência da Pecking Order Theory com sua hierarquização de fontes de financiamento propostas por Myers (1984) e Myers e Majluf (1984), resultados que estão em linha com os estudos de Medeiros e Daher (2005); Bastos e Nakamura (2009); Correa, Basso e Nakamura (2013).

Quando se analisou o financiamento externo como fonte secundária, o endividamento seria a primeira opção que correspondeu a 51\%, seguido pela emissão de ações, que correspondeu a 36\%. Nesse sentido, conclui-se que daqueles $49 \%$ que adotaram como forma de financiamento a emissão de dívidas, ao optar por outras formas de financiamentos, se tem preferência pela emissão de ações e, posteriormente, pelo autofinanciamento. Assim, observa-se a composição do perfil da estrutura de financiamento das companhias investigadas, o que atende a questão de pesquisa proposta neste estudo.

Ao mesmo tempo, observa-se que tanto a Pecking Order theory com a lógica da hierarquização da forma de financiamento quanto a Trade Off theory com a lógica do custo-benefício do capital e seu respectivo custo, podem ser utilizadas para se entender as formas de financiamentos escolhidas pelas companhias brasileiras.

Com esses resultados, conclui-se que mesmo o Brasil adotando um modelo contábil, nesse caso, o padrão internacional de contabilidade, que é de um contexto com característica common Law, com forte participação de recursos de investidores na estrutura de capital das companhias, o perfil de financiamento das companhias investigadas não acompanhou tal lógica, ou seja, as companhias ainda são financiadas preferencialmente por instituições financeiras (bancos), o que evidencia a fraca influência desse modelo contábil na forma de financiamento, e que corrobora com os achados de Silva (2015).

Quanto à comparação com estudos anteriores que abordaram a mesma temática e os mesmos procedimentos metodológicos, porém em períodos e amostras diferentes, os resultados do presente 
estudo foram consistentes com os estudos de Singh (1995), Zonenschain (1998) no período de curto prazo (1995 - 1996), e Moreira e Puga (2001), quando os resultados apontam o autofinanciamento como fonte principal.

Com esses resultados, observa-se que antes e depois da adoção no novo padrão contábil baseado em IFRS, a forma de financiamento das companhias da amostra, em sua essência, não se alterou. Assim, tais evidências permitem concluir que esse padrão contábil não se tornou um fator relevante para definir a forma como as companhias se financiam, mesmo sendo um padrão que incentiva o financiamento através da emissão de ações.

Quanto às dificuldades encontradas para a realização deste estudo, chama-se atenção para os dados incompletos das companhias, provocando painéis desbalanceados, e que após o teste de consistência levou a amostra a ser consideravelmente afetada, pois houve uma significativa redução na quantidade de companhias para serem investigadas. Tal redução pode apresentar uma deformidade na realidade das informações das companhias abertas no Brasil durante o período de análise.

Por fim, como sugestões para pesquisas futuras, no sentido de continuar a investigação sobre a temática, sugere-se análises complementares em relação aos períodos pesquisados, ou seja, quais outros fatores, além da mudança de padrão contábil, poderiam ajudar a entender os resultados. Dentre esses fatores pode-se analisar o período de crise da bolsa de valores em 2008, o avanço das IPOs, o contexto político brasileiro e outros fatores que poderiam indicar mudança de comportamentos quanto à forma de financiamento das companhias brasileiras de capital aberto.

\section{REFERÊNCIAS}

Albanez, T., \& Valle, M. R. (2009). Impactos da assimetria de informação na estrutura de capital de empresas brasileiras abertas. Revista Contabilidade E Finanças - USP , 20 (51), 6 - 27.

Albuquerque, E. M., \& Sicsú, J. (2000). Inovação institucional e estímulo ao investimento privado. São Paulo em Pespectiva, 14 (3), 108 - 114.

Ball, R., Kothari, S. P., \& Robin, A. (2000). The effect of international institutional factors on properties of accounting earnings. Journal of Accounting and Economics, 29, $1-51$.

Bastos, D. D., \& Nakamura, W. T. (2009). Determinantes da estrutura de capital das companhias abertas no Brasil, México e Chile no período 2001-2006. Revista Contabilidade E Finanças USP , 20 (50), 75-94.

Brealey, R.; Myers, S., \& Allen, F. (2006). Principles of corporate finance. 8. ed. Irwin: Mc Graw Hill.

Brito, G. A. S., Corrar, L. J., \& Batistella, F. D. (2007). Fatores determinantes de estrutura de capital das maiores empresas que atuam no Brasil. Revista Contabilidade \& Finanças - USP, 18 (43), 9 -19 .

Brito, R. D., \& Lima, M. R. (2005). A escolha da estrutura de capital sob fraca garantia legal: o caso do Brasil. Revista Brasileira de Economia, 59 (2), 177 - 208.

Correa, C. A., Basso, L. F. C., \& Nakamura, W. T. (2013). A Estrutura de Capital das Maiores Empresas Brasileiras: Análise Empírica das Teorias de Pecking Order e Trade-Off, Usando Panel Data. Revista de Administração Mackenzie, 14 (4), 106-133.

Costa, F. M., Lopes, A. B., \& Costa, A. C. O. (2006). Conservadorismo em cinco países da América do Sul. Revista Contabilidade E Finanças - USP, 17 (41), 7 - 20. 
Durand, D. (1952). Cost of debt and equity funds for business: trends and problems of measurement. In Conference on Research in Business Finance, New York.

Farias, K. T. R., Farias, M. R. S. (2012). In A. B. Lopes (org.). Contabilidade internacional: contabilidade e finanças no Brasil: estudos em homenagem a Eliseu Martins (Cap.6. pp. 138-169). São Paulo: Atlas S/A.

França, J. A., Santos, S. I. F., Sandoval, W. S., \& Santos, A. P. (2016). Estrutura de financiamento das firmas de energia elétrica no Brasil: uma abordagem à Pecking Order Theory (POT). Revista de Contabilidade e Organizações, 10 (27), 58 - 70.

Fonseca, C. V. C., Silveira, R. L. F., \& Hiratuka, C. (2016). A relação entre a governança corporativa e a estrutura de capital das empresas brasileiras no período 2000 - 2013. Enfoque: reflexão contábil, 35 (2), 35 - 52.

Harris, M. \& Raviv, A. (1991). The theory of optimal capital structure. Journal of Finance, 48, 297356.

Iquiapaza, R. A., Amaral, H. F., \& Araújo, M.S.B. (2008). Testando as previsões da pecking order theory no financiamento das empresas brasileiras: uma nova metodologia. Revista de Administração Mackenzie, 9 (3), 157-183.

Jensen, M. C., \& Meckling, W. H. (1976). Theory of the firm: managerial behavior, agency costs and ownership structure. Journal of Financial Economics, 3 (4), 305-360.

Kaveski, I. D. S., Hall, R. J., Degenhart, L., Vogt, M., \& Hein, N. (2015). Determinantes da estrutura de capital das empresas brasileiras de capital aberto do agronegócio: um estudo a luz das teorias Trade Off e Pecking order. EEG Economia e Gestão, 15 (41), 135 - 148.

Lopes, A. B., \& Walker, M. (2008). Firm-level incentives and the informativeness of accounting reports: an experiment in Brazil [Working Paper]. Social Science Research Network.

Medeiros, O.R., \& Daher, C. E. (2005). Testanto a teoria de hierarquização de fontes de financiamento nas empresas brasileiras. Revista Contabilidade E Finanças - USP, 16 (37), 37-45.

Modigliani, F., \& Miller, M. H. (1958). The cost of capital, corporation finance and the theory of investment. The American economic review, 48 (3), 261-297.

Modigliani, F. \& Miller, M. H. (1963). Corporate income taxes and the cost of capital: a correction. The American Economic Review, 53(3), 433-443.

Moreira, M.M., \& Puga, F.P. (2001). Como a Indústria financia seu crescimento: Uma Análise do Brasil Pós-Plano Real. Revista de Economia Contemporânea, 5, 35-67.

Myers, S. C., \& Majluf, N. S. (1984). Corporate financing and investment decisions when firms have information that investors do not have. Journal of Financial Economics, 13 (2), 187-221. 
Nascimento, O. C. (2012). Estudo das decisões de estrutura de capital corporativo no novo mercado e nos níveis de governança da BMEFBovespa à luz das teorias Trade-Offe Pecking Order (Dissertação de mestrado, Programa Multi-institucional e inter-regional de pós-graduação em ciências contábeis, Universidade de Brasília, Universidade Federal da paraíba, Universidade federal do Rio Grande do Norte). Recuperado de http://repositorio.unb.br/handle/10482/10989.

Nobes, C. (1998). Towards a general model of the reasons for international differences in financial reporting. Abacus, 34 (2), 162-187.

Padilha, D. F., Michels, A., \& Silva, T. P. (2015, Maio). Determinantes capital structure high-tech companies G-20 countries. International conference on information systems $\mathcal{E}$ technology management, São Paulo, SP, Brasil, 20-22.

Perobelli, F. F. C., \& Famá, R. (2003). Determinantes da estrutura de capital: aplicação a empresas de capital aberto brasileiras. Revista de Administração contemporânea, 7 (1), 9 - 35.

Procianoy, J. L., \& Schnorrenberger, A (2004). A influência da estrutura de controle nas decisões de estrutura de capital das companhias brasileiras. Revista Brasileira de Economia, 58 (1), 121 146.

Silva, A. R. P. (2015). Conservadorismo e herança institucional de financiamento das companhias abertas do Brasil (Tese de doutorado, Programa Multi-institucional e inter-regional de pós-graduação em ciências contábeis, Universidade de Brasília, Universidade Federal da paraíba, Universidade federal do Rio Grande do Norte). Recuperado de http://repositorio.unb.br/handle/10482/20442.

Silva, T. P., Gonçalves, M., \& Leite, M. (2016). Eficiência econômica de empresas de tecnologia latinoamericanas sob a perspectiva da sua estrutura de capital. Revista Contabilidad y Negocios, $11(21), 45-67$.

Singh, A. (1995). Corporate Financial Patterns in Industrializing Economies: a Comparative International Study [Working Paper № 14328]. IFC Technical Paper 2, Washington D.C.

Singh, A., \& Hamid, J. (1992). Corporate Financial structures in developing countries [Working Paper № 10663]. ICF Technical Paper 1, Washington D.C.

Tani, B. B., \& Albanez, T. (2016). Decisões de financiamento das companhias listadas nos diferentes segmentos de governança da Bm\&Fbovespa according to pecking order theory. Contabilidade, gestão e governança, 19 (2), 317 - 334 .

Zonesnchain, C. N. (1998). Estrutura de capital das empresas no Brasil. Revista do BNDS, 5 (10), 63 92.

Zysman, J. (1983). Government, Market and growth: financial systems and the politics of industrial change. Ithaca, N.Y:Cornell University Press. 